\title{
Effect of Handedness and Footedness on Some Motoric Characteristics in Amateur Soccer Players
}

\author{
Deniz Özge Yüceloğlu Keskin ${ }^{1}$, Osman İmamoğlu ${ }^{1}$, Menderes Kabadayı ${ }^{1}$ \\ ${ }^{1}$ Yaşar Doğu Faculty of Sports Sciences, Ondokuz Mayıs University, Samsun, Turkey \\ Correspondence: Osman İmamoğlu, Yasar Dogu Faculty of Sport Science, Ondokuz Mayıs University, 55105, Samsun, \\ Turkey.
}

Received: August 19, 2019

doi:10.11114/jets.v7i12.4461
Accepted: September 11, $2019 \quad$ Online Published: September 16, 2019

URL: https://doi.org/10.11114/jets.v7i12.4461

\begin{abstract}
The present study aims to compare the strength of right and left legs and reaction times of soccer players depending on their hand and foot preferences. The study included 92 volunteers chosen from amateur soccer players. The measurements conducted on the subjects were anthropometric characteristics, foot reaction times (sound, light) and right and left foot squat parameters. The t-test was used for statistical procedures. Among the amateur soccer players who participated in this study, it was found that $19.57 \%$ used left hand and $67.39 \%$ used right hand as preferred. Soccer players using both hands equally were found with a rate of $13.4 \%$. In terms of foot preference, it was found that $22.83 \%$ of the participants used left foot and $43.48 \%$ of the participants used right foot as preferred. The soccer players using both feet equally was found as $33.70 \%$. No significant difference was found between right handers and left handers in reaction time measurements when the soccer players were grouped by hand preference. When compared with left footed players $(0.29 \mathrm{sec})$, only the right foot sound reaction time of right footed players was significantly shorter $(0.21 \mathrm{sec})$ at $\mathrm{p}<.05$ level. Statistically significant correlation was found between soccer players' hand and foot preference at a level of $p<0.01$. Left footed players had significantly higher left leg mean squat $(37.19 \mathrm{~kg})$ when compared with right footed players $(32.27 \mathrm{~kg})$. No significant difference was found between right footed $(35.36 \mathrm{~kg})$ and left footed (33.98) subjects in terms of mean of right leg squat. Conclusion: According to the hand preference, the proportion of those who use equally two feet increased. Reaction times and force's squat of the dominant hands and feet were better. Training programs for soccer players planned according to individual characteristics including footedness may result in performance increase and decrease in injury as a result of reduced strength and reaction time asymmetry between legs and arms.
\end{abstract}

Keywords: soccer, single leg squat strength, handedness, footedness

\section{Introduction}

While about $75 \%$ of the human population is strongly right-handed, about $90 \%$ is predominantly right-handed. There is a great deal of variability within the remaining $10 \%$. While some are strongly left-handed, others use left-hand for some activities and right hand for some others (Gürsoy et al., 2009; Raymond et al., 1996). It is commonly believed that people who use their left-hand have better developed motor, attentional and spatial functions (Geschwind and Galaburda, 1987; Nass and Gazzaniga, 1987). A positive association between left-handedness and cognitive ability of mathematically talented individuals has been shown in previous studies (Coren 1995). A previous study on university students showed a positive association between left-handedness and divergent thinking in male students (Beratis et. al 2013). It has been reported in many studies that the rate of dominant left-handed athletes is high among high-level athletes in baseball, tennis, fencing, cricket fight sports boxing and wrestling (Akça et al., 2015).Temporal distribution of handedness should be investigated to understand the impact of handedness on performance. To give an example, frequencies of left-handed pitchers and batters increased logarithmically with time (between 1876 and 1985) and attained a stable overrepresentation at 30\% in Major League Baseball (Wood \& Aggleton 1989). As another example, left-handed batsmen were more successful than the right-handed batsmen 2007 ICC Cricket World Cup and the rate of left-handed batsmen was about 50.5\% in most successful teams (Brooks et al 2004). A higher proportion (20\%) of professional cricketers were found to bowl with their left hand, which brought to mind that left-handed advantage is tactical (Wood \& Aggleton 1989). 
It can be said that "Preferred hand use is not an easily malleable trait" (Halpern \& Coren, 1993). In addition, left-handed people have clear and visible differences from right-handed people. Raymond et.al.,(1996) reported that there were a significantly higher percentage of left-handed athletes in sports like tennis (15\%), table tennis (41\%), and fencing (50\%) when compared with the general population. Most of the time, sports teams want to have left-handed players or athletes. Left-handed players are sought for the team in sports like baseball (Trotter, 1974), basketball, and volleyball. This left-handed advantage can also be seen in some individual sports such as golf and combat sports (Onion, 2005). Left handed/footed athletes can be seen to be over represented compared to general population in many interactive sports. Some interactive sports which have higher rate of left-handed/footed athletes compared to general population can be listed as tennis (Holtzen, 2000), baseball (Goldstein \& Young, 1996), cricket (Brooks et al, 2004), fencing (Harris, 2007) and volleyball (Loffing, 2012). However, the same over representation cannot be observed in sports that are not interactive, such as gymnastics, darts, and archery (Grouios, 2004). Depending on the type of sport, the incidence of left-handedness/footedness can vary between $13 \%$ and $36 \%$. It can be clearly seen that left-handed or footed people are over represented in the sports compared to general population (13-25\% and 8-10\%). (Akpinar and Bicer, 2014). Many different parameters affect the success of soccer players. These vary from psychological to anthropometric and genetic characteristics. For example, colors are effective in visual perception (Yamaner and Imamoğlu, 2018). Red color attracts attention and can increase aggression. White color is soothing and green color can help recovery for soccer players (İmamoğlu, 2010; İmamoğlu, 2011). A high proportion of left-handers have been reported among top sportsmen and sports women (Gürsoy et al., 2009). Fewer people have a stronger left-hand and leg preference than right-hand and right leg preference. A greater number of people are classified as right-handed and using right leg (Ziyagil et al, 2015). Being either right-handed or left-handed may sometimes be very effective and determinative (Erhan et al., 2018). These muscles are frequently used in football. Depending on the amount of hand and leg usage as well as the athlete's hand and leg preference, lateralization is important for success in soccer.

Purpose and hypotheses

The present study aims to compare the strength of right and left legs and reaction times of soccer players depending on their hand and foot preferences. Another aim of this study is to investigate the change in right and left hand or foot preference depending on usage.

\section{Method}

\subsection{Participants}

92 amateur football players were included in the study and two-handed soccer players were excluded from the evaluation. The soccer players were left-handed and right-handed members of a male team from the third highest amateur league in Samsun. In handedness, 18 soccer players were using the left hand and 62 players were using the right hand. The soccer players who used both hands was 12 people. In footedness, 21 soccer players were using the left foot and 40 players were using the right foot. The soccer players who used both legs was 31_people. The average age of the players was 22.17 years and at the time they had been playing in their clubs for an average of 12.3 years. Those who used both hands and feet evenly were not included in the evaluation except the first table.

\subsection{Measurements}

Handedness: In order to measure handedness, Edinburg Inventory (Oldfield) handedness test was used (Dane \&Erzurumluoglu, 2003). During the test, the hand which writes, draws, and grabs the scissors, toothbrush, spoon, and hammer, and grabs the matchstick while lighting the fire, and grabs the lid while unpacking the box was determined. The results of the test were written on the data collection form. The answers of the participants were scored between +100 and -100 according to the Geschwind score. The questions were rated as $-10,-5,0,+5$, and +10 , respectively. In a total of 10 questions, always with the left hand was given -10 , usually with left hand was given -5 , with both hands was given 0 (zero), usually with right hand was given 5 and always with right hand was given 10 points. Accordingly, $-100 /-20$ was accepted as left-handed, $-20 /+20$ as two-handed, while $+20 /+100$ was accepted as right-handed.

Footedness: In order to determine the foot preference, in addition to the ball hitting and stair climbing, the ball has been controlled by foot, dribbling and passing, and a total of five questions have been asked. Always the right foot was given "20 points", usually the right foot was given " 10 points", two feet was given " 0 points", usually left foot was given "- 10 points" and always left foot was given "-20 points". A total of 100 points were evaluated. Those with 0-100 points were recorded as right-footed and those with a score less than zero were recorded as left-footed.

Body Weight: The players' weights were measured by a weighing device which measures with a $\pm 0,1 \mathrm{~kg}$ sensitivity (Tanita 401 A Japan)

Body Height: After the head was put to the Frankfort plane with a deep inspiration, the measurements between vertex point of head and the feet, with no shoes, were taken to measure the height by using a stadiometer (Holtain UK). 
Leg Height: When the soccer player was standing up, the end of the scalpel was taken to measure the coaxes and the other end to the base.

Measurements of skinfold:

Measurements of skinfold and subcutaneous fat tissue thickness were obtained from eight parts of the body using a "holtain" skinfold caliper (0, $2 \mathrm{~mm}$ ), (biceps, triceps, sub-scapula, supra-iliac, abdominal, chest, thigh, calf).

Biceps: midpoint between the acromion and olecranon protrusions on the front center line of the arm.

Triceps: midpoint between the acromion and olecranon protrusions on the posterior center line of the arm.

Subscapular: 1 to $2 \mathrm{~cm}$ below the inferior angle of the scapula.

Supra-iliac: just above the intersection of the anterior axillary line with the anterior superior iliac spine.

Abdominal: Next to the belly button.

Chest: One-half the distance between the anterior axillary line (crease of the underarm) and the nipple.

Thigh: Midway between the proximal border of the patella (upper knee) and the inguinal crease (hip)

Calf: Maximum circumference of calf on the midline of medial border

Standing Long Jump Test: To conduct the standing long jump test, the players stood with their feet next to each other, while the tips of their toes were kept before the jumping line; then they jumped forward as far as they could, with the knees bent and hands swinging to and fro. Two trials, the best value of which was recorded, was made.

Standing Long Jump Test with Single Leg: Soccer player jumped from the back of the marked line to the farthest point where one can reach with one foot.

Three Steps to One Leg Horizontal Jumping Test: Soccer player jumped from the back of the marked line in three steps without waiting with one foot in the back to the farthest point that one can reach

Determining the Maximal Force: A certain procedure was followed for the players during the squat movement.

Reaction Time Measurement: Visual and auditory reaction time was measured by the New test Reaction Timer 1/100. Right - left hand response and right-left foot response times were measured against sound and light warnings.

\subsection{Statistical Analeyse}

SPSS 22.0 software package was used to conduct all statistical analyses. Mean \pm standard deviation was used for numerical variables, while $\mathrm{n}$ and percentage were used for categorical variables to show the descriptive statistics. The $\mathrm{t}$-test was used for statistical procedures. $\mathrm{p}<0.05$ level was considered as statistically significant.

\section{Results}

Table 1. \% distribution of amateur soccer players according to Handedness and Footedness

\begin{tabular}{llll}
\hline Parameters & & $\mathrm{n}$ & $\%$ \\
\hline Handedness & Left-Handed & 18 & 19.57 \\
\cline { 2 - 4 } & Right-Handed & 62 & 67.39 \\
\cline { 2 - 4 } & Two - Handed & 12 & 13.04 \\
\cline { 2 - 4 } & Total & 92 & 100.00 \\
\hline Footedness & Left- Footed & 21 & 22.83 \\
\cline { 2 - 4 } & Right- Footed & 40 & 43.48 \\
\cline { 2 - 4 } & Two- Footed & 31 & 33.70 \\
\cline { 2 - 4 } & Total & 92 & 100.00
\end{tabular}

Among the amateur soccer players who participated in this study, it was found that $19.57 \%$ used left hand and $67.39 \%$ used right hand as preferred. Soccer players using both hands equally was found as $13.4 \%$. In terms of foot preference, it was found that $22.83 \%$ used left foot and $43.48 \%$ used right foot as preferred. Soccer players using both feet equally was found as $33.70 \%$. 
Table 2. Comparison of lateralization distribution of various physical characteristics of soccer players according to hand preference

\begin{tabular}{|c|c|c|c|c|c|}
\hline Parameters & & $\mathrm{n}$ & Mean & $\begin{array}{l}\text { Std. } \\
\text { Deviation }\end{array}$ & $\mathrm{t}$ \\
\hline \multirow[t]{2}{*}{ Height (cm) } & Left-Handed & 18 & 174.92 & 5.87 & \multirow[t]{2}{*}{-0.15} \\
\hline & Right-Handed & 62 & 175.66 & 6.12 & \\
\hline \multirow[t]{2}{*}{ Leg Height $(\mathrm{cm})$} & Left-Handed & 18 & 91.81 & 2.74 & \multirow[t]{2}{*}{-0.95} \\
\hline & Right-Handed & 62 & 92.55 & 2.54 & \\
\hline \multirow[t]{2}{*}{ Weight (kg) } & Left-Handed & 18 & 75.54 & 12.10 & \multirow[t]{2}{*}{-0.19} \\
\hline & Right-Handed & 62 & 76.12 & 9.78 & \\
\hline \multirow[t]{2}{*}{ Age (Years) } & Left-Handed & 18 & 22.15 & 2.15 & \multirow[t]{2}{*}{0.48} \\
\hline & Right-Handed & 62 & 22.19 & 2.13 & \\
\hline \multirow[t]{2}{*}{8 skinfold sum $(\mathrm{mm})$} & Left-Handed & 18 & 87.02 & 23.54 & \multirow[t]{2}{*}{1.35} \\
\hline & Right-Handed & 62 & 78.76 & 25.29 & \\
\hline
\end{tabular}

No statistically significant difference was found in the comparison of the lateral distribution of various physical characteristics of football players according to hand preferences ( $p>0.05)$.

Table 3. Comparison of lateralization distribution of various physical characteristics of soccer players according to foot preference

\begin{tabular}{|c|c|c|c|c|c|}
\hline Parameters & & $\mathrm{n}$ & Mean & Std. Deviation & $\mathrm{t}$ \\
\hline \multirow[t]{2}{*}{ Height (cm) } & Left-Footed & 21 & 174.12 & 5.97 & \multirow[t]{2}{*}{-0.57} \\
\hline & Right-Footed & 40 & 175.76 & 6.33 & \\
\hline \multirow[t]{2}{*}{ Leg Height $(\mathrm{cm})$} & Left-Footed & 21 & 91.72 & 2.74 & \multirow[t]{2}{*}{-1.72} \\
\hline & Right-Footed & 40 & 92.16 & 2.54 & \\
\hline \multirow[t]{2}{*}{ Weight (kg) } & Left-Footed & 21 & 75.91 & 11.10 & \multirow[t]{2}{*}{-0.13} \\
\hline & Right-Footed & 40 & 76.03 & 9.17 & \\
\hline \multirow[t]{2}{*}{ Age (Years) } & Left-Footed & 21 & 22.25 & 2.15 & \multirow[t]{2}{*}{-0.29} \\
\hline & Right-Footed & 40 & 22.36 & 2.13 & \\
\hline \multirow[t]{2}{*}{8 skinfold sum $(\mathrm{mm})$} & Left-Footed & 21 & 79.85 & 23.54 & \multirow[t]{2}{*}{1.35} \\
\hline & Right-Footed & 40 & 81.49 & 25.29 & \\
\hline
\end{tabular}

No statistically significant difference was found in the comparison of the lateral distribution of various physical characteristics of football players according to foot preferences ( $p>0.05)$. 
Table 4. Comparison of lateralization distribution of various motor characteristics of soccer players

\begin{tabular}{|c|c|c|c|c|c|}
\hline Parameter & & $\mathrm{n}$ & Mean & $\begin{array}{l}\text { Std. } \\
\text { Deviation }\end{array}$ & $\mathrm{t}$ \\
\hline \multirow[t]{2}{*}{ Right foot reaction time, light (sec) } & Left-Handed & 18 & 0.26 & 0.02 & \multirow[t]{2}{*}{1.91} \\
\hline & Right-Handed & 62 & 0.21 & 0.03 & \\
\hline \multirow[t]{2}{*}{ Left foot reaction time, light $(\mathrm{sec})$} & Left-Handed & 18 & 0.19 & 0.31 & \multirow[t]{2}{*}{-0.63} \\
\hline & Right-Handed & 62 & 0,20 & 0.32 & \\
\hline \multirow{2}{*}{$\begin{array}{l}\text { Right foot reaction time, sound } \\
\text { (sec) }\end{array}$} & Left-Handed & 18 & 0.29 & 0.02 & \multirow[t]{2}{*}{$2.12 *$} \\
\hline & Right-Handed & 62 & 0.21 & 0.03 & \\
\hline \multirow[t]{2}{*}{ Left foot reaction time, sound (sec) } & Left-Handed & 18 & 0.22 & 0.03 & \multirow[t]{2}{*}{0.32} \\
\hline & Right-Handed & 62 & 0.21 & 0.04 & \\
\hline \multirow[t]{2}{*}{ Right leg squat (kg) } & Left-Handed & 18 & 35.06 & 7.51 & \multirow[t]{2}{*}{0.41} \\
\hline & Right-Handed & 62 & 35.12 & 7.55 & \\
\hline \multirow[t]{2}{*}{ Left leg squat $(\mathrm{kg})$} & Left-Handed & 18 & 34.27 & 7.62 & \multirow[t]{2}{*}{0.40} \\
\hline & Right-Handed & 62 & 34.19 & 7.59 & \\
\hline \multirow[t]{2}{*}{ Right leg horizontal jumping $(\mathrm{cm})$} & Left-Handed & 18 & 178.15 & 21.05 & \multirow[t]{2}{*}{0.87} \\
\hline & Right-Handed & 62 & 178.35 & 20.19 & \\
\hline \multirow[t]{2}{*}{ Left leg horizontal jumping $(\mathrm{cm})$} & Left-Handed & 18 & 177.89 & 20.42 & \multirow[t]{2}{*}{-0.16} \\
\hline & Right-Handed & 62 & 176.91 & 20.18 & \\
\hline \multirow{2}{*}{$\begin{array}{l}3 \text { steps consecutive horizontal } \\
\text { jumping with the right leg }(\mathrm{cm})\end{array}$} & Left-Handed & 18 & 580.19 & 63.24 & \multirow[t]{2}{*}{0.39} \\
\hline & Right-Handed & 62 & 581.16 & 62.59 & \\
\hline \multirow{2}{*}{$\begin{array}{l}3 \text { steps consecutive horizontal } \\
\text { jumping with the left leg }(\mathrm{cm})\end{array}$} & Left-Handed & 18 & 569.10 & 62.55 & \multirow[t]{2}{*}{-0.10} \\
\hline & Right-Handed & 62 & 568.47 & 61.89 & \\
\hline
\end{tabular}
$* \mathrm{p}<0.5$

A significant difference was found in reaction times of right foot for sound in comparing lateralization distribution of various motor characteristics of soccer players according to hand preference ( $\mathrm{p}<0.05$ ). No statistically significant difference was found in other parameters ( $\mathrm{p}>0.05)$.

Table 5. Comparison of lateralization distribution of various motor characteristics of soccer players

\begin{tabular}{|c|c|c|c|c|c|}
\hline Parameter & & $\mathrm{n}$ & Mean & $\begin{array}{l}\text { Std. } \\
\text { Deviation }\end{array}$ & $\mathrm{t}$ \\
\hline \multirow[t]{2}{*}{ Right foot reaction time, light (sec) } & Left-Footed & 21 & 0.24 & 0.12 & \multirow[t]{2}{*}{1.05} \\
\hline & Right-Footed & 40 & 0.19 & 0.13 & \\
\hline \multirow[t]{2}{*}{ Left foot reaction time, light (sec) } & Left-Footed & 21 & 0.20 & 0.31 & \multirow[t]{2}{*}{-0.45} \\
\hline & Right-Footed & 40 & 0.19 & 0.30 & \\
\hline \multirow{2}{*}{$\begin{array}{l}\text { Right foot reaction time, sound } \\
(\mathrm{sec})\end{array}$} & Left-Footed & 21 & 0.27 & 0.02 & \multirow[t]{2}{*}{1.29} \\
\hline & Right-Footed & 40 & 0.19 & 0.03 & \\
\hline \multirow[t]{2}{*}{ Left foot reaction time, sound (sec) } & Left-Footed & 21 & 0.21 & 0.04 & \multirow[t]{2}{*}{0.37} \\
\hline & Right-Footed & 40 & 0.20 & 0,04 & \\
\hline \multirow{2}{*}{ Right leg squat (kg) } & Left-Footed & 21 & 35.36 & 7.41 & \multirow[t]{2}{*}{0.66} \\
\hline & Right-Footed & 40 & 33.98 & 7.65 & \\
\hline \multirow[t]{2}{*}{ Left leg squat (kg) } & Left-Footed & 21 & 37.19 & 8.62 & \multirow[t]{2}{*}{$2.32 *$} \\
\hline & Right-Footed & 40 & 32.27 & 7.29 & \\
\hline \multirow[t]{2}{*}{ Right leg horizontal jumping $(\mathrm{cm})$} & Left-Footed & 21 & 175.35 & 21.05 & \multirow[t]{2}{*}{-0.88} \\
\hline & Right-Footed & 40 & 179.15 & 20.19 & \\
\hline \multirow[t]{2}{*}{ Left leg horizontal jumping $(\mathrm{cm})$} & Left-Footed & 21 & 179.89 & 20.42 & \multirow[t]{2}{*}{-0.90} \\
\hline & Right-Footed & 40 & 176.21 & 21.18 & \\
\hline \multirow{2}{*}{$\begin{array}{l}3 \text { steps consecutive horizontal } \\
\text { jumping with the right leg }(\mathrm{cm})\end{array}$} & Left-Footed & 21 & 565.95 & 63.12 & \multirow[t]{2}{*}{-0.85} \\
\hline & Right-Footed & 40 & 581.09 & 61.59 & \\
\hline \multirow{2}{*}{$\begin{array}{l}3 \text { steps consecutive horizontal } \\
\text { jumping with the left leg }(\mathrm{cm})\end{array}$} & Left-Footed & 21 & 579.14 & 62.05 & \multirow[t]{2}{*}{-1.19} \\
\hline & Right-Footed & 40 & 558.47 & 60.89 & \\
\hline
\end{tabular}

A significant difference was found in the right leg squat value in comparison of the distribution of various motor characteristics of soccer players according to hand preference $(\mathrm{p}<0.05)$. There were no statistically significant differences in other parameters $(\mathrm{p}>0.05)$. 
Table 6. Levels of relationship between some parameters of football players

\begin{tabular}{lc}
\hline Parameter & Correlation \\
\hline Handedness- Footedness & $0.321^{*}$ \\
\hline Right leg squat - reaction time of the right foot against the light stimulus & $0.307^{*}$ \\
\hline Right leg squat - reaction time of the left foot against the sound stimulus & $-0.296^{*}$ \\
\hline Left leg squat - reaction time of the right foot against the light stimulus & $0.324^{*}$ \\
\hline Left leg squat - reaction time of the left foot against the sound stimulus & $-0.319^{*}$ \\
\hline
\end{tabular}
$* \mathrm{p}<0.5$

\section{Discussion}

In $95 \%$ of the population, the motor fields controlling the hands are in the left hemisphere and because of this most people use their right hands commonly (Leong, 1980). Left hemisphere is where motor spaces are more dominantly located, which enable approximately $95 \%$ of the humans to control their hands. This is why a larger part of people use their right hand (Turan, 2010). Approximately 15\% of professional tennis players are left-handers, while only $11 \%$ of the general population is. The contrast in sports such as baseball, cricket, boxing, table-tennis and fencing is higher. To give an example, often $30 \%$ or more of the top level fencers, table-tennis players and specialist batsmen in cricket are left handed in their respective sports or positions (Fagan et al., 2017). In another study conducted by

Loffing et al., (2014) with 903 athletes from various branches such as fencing, bowling, and boxing, it was found that $10.05 \%$ of the male athletes used their left hands dominantly, while $7.88 \%$ of the female athletes used their left hands dominantly, in higher rates when compared to general population. $12.4 \%$ of total athletes were found to be left-handed in Cingoz et al.'s (2018) study. It was reported by Erhan et al. (2018) that 16.5\% of the athletes were left-handed, $75.7 \%$ were right-handed and 7.8\% used both hands. İmamoğlu and Kilcigil (2007) found soccer players use left foot with a rate of $16.7 \%$, while $83.3 \%$ use right foot when they play football. In this study, in terms of hand preference, the proportion of those who used two feet equally increased. This may be due to the use of both legs of the soccer players. When it is considered that hand and foot preferences can be changed through training, it is possible to say that while developing behaviors specific to a branch, not only genes but also environmental factors, training, and experiences are influential (Erhan et al., 2018). In this study, no statistically significant difference was found between heights, leg length, body weights, ages and 8 skinfold measurements in terms of hand preference of soccer players ( $p>0.05$ ). Again, in terms of foot preference of soccer players, no statistically significant difference was found between height, leg length, body weight, age and 8 skinfold measurements ( $p>0.05$ ). In this study, no difference was found between left-handers and right-handers in terms of anthropometric characteristics of the soccer players. The simple reaction time, which was shown to be dependent on the brain hemisphere dominance, was reported to be superior (more rapid) in the right-handers than the left (Dane and Erzurumluoglu, 2003). Al Awamleh et al., (2013) reported that in terms of simple Auditory Reaction time high tone, and visual choice reaction time movement time, significant differences were found between right-handed and left-handed. Peters and Durding (1979) conducted a study to compare right- and left-handers for speed of tapping by each hand. The results of the study showed that handedness groups were almost similar In terms of the preferred hand, while left-handers were significantly faster than right-handers with their non-preferred hand. It is currently fashionable to stress the weakness of the association between hand preference and hand skill (Porac and Coren, 1981). Cingoz et al., (2018) reported a weak association between dominant hand preference of left-handed female karate and taekwondo athletes in terms of winning medals, while no association was found between male athletes.

In this study, a significant difference was found in reaction times of right foot for sound in comparing lateralization distribution of various motor characteristics of soccer players according to hand preference. No statistically significant difference was found in other parameters. In our study, the right foot reaction time against the sound stimulus was 0.29 $\mathrm{sec}$ in the left handers and $0.21 \mathrm{sec}$ in the right hand dominated soccer players. When football players were grouped according to hand preference, no significant difference was found in reaction time between right-handed and left-handed players. These values found in handball and badminton athletes in a study conducted with the left handers conflict with the superiority of the reaction time (Dane and Erzurumluoglu, 2003). The reason for the difference between our study and other studies may be the comparison of the measured foot reaction in our study with the reported hand reaction time in other studies.

These findings are not supported by Fisekcioglu (2011) who reported that in terms of simple Auditory Reaction time, left -handed taekwondo players perform better than right -handed ones. Selçuk et al., (2019) found that bilateral footed males were $2.81 \%$ faster than unilateral footed males. Researchers (Grace et al. 1984) have shown that the current 
dominant and non-dominant leg force difference in athletes greater than $10 \%$ may cause injury. In this study, a significant difference was found in the right leg squat value in comparison of the distribution of various motor characteristics of soccer players according to hand preference. There were no statistically significant differences in other parameters. In our study, the left leg squat force of the soccer players with the left foot dominant and the right leg squat force of the right leg dominant is better. In our study, hand preference and foot preference relationship levels were found to be significant at $\mathrm{p}<0.05$ level. Again, the mean of right leg squat was positively associated with the reaction time of the right foot against the light stimulus and was negatively associated with the reaction time of the left foot to the sound stimulus. In addition, the left leg squat was positively associated with the reaction time of the right foot against the light stimulus and was negatively correlated with the reaction time of the left foot to the sound stimulus. There was a statistically significant correlation between soccer players' hand and foot preference at a level of $p<0.01$. The left leg mean squat $(37.19+8.62 \mathrm{~kg})$ of left footed players was found to be significantly higher than that of right footed players $(32.27+7.29 \mathrm{~kg})$. No significant difference was found between right footed $(35.36+7.41 \mathrm{~kg})$ and left footed $(33.98+7.65$ $\mathrm{kg}$ ) subjects in terms of average right leg squat. It was found that left footed players had more symmetrical leg strength than right footed players. The results of our study contradict with the study of Singh (1970), who reported that the left leg dominants had asymmetry due to the great strength of their left legs. This may be due to the fact that the strength of the legs of the right leg dominance is more asymmetric than the left. A good player should be able to kick the ball well with both legs. However, bilateral differences occur even in top-level players who cannot score when it is not possible to play the ball with their preferred leg. Asymmetries in muscle strength, muscle activation, and muscle thickness between the two legs have been reported in previous studies (Gstöttner et al., 2009). When referring to lateral preferences in sports, researchers should pay more attention while using the term 'handedness', especially when dealing with sport tasks for which relationships with handedness are low. When testing for an excess of 'left-oriented' athletes in sports, task-specific reference values should be used. Also, for reasons discussed above, the term 'handedness' should be used more carefully within research on sport-specific lateral preferences. Future studies should be focused on both preference and performance measures as well as performance demands associated with the domain of interest in order to investigate the impact of handedness and task-specific lateral preference on high achievement in sports or related behavioral domains (Lofting et al., 2014). Erhan et al., (2018) suggested that hand and foot preferences can be changed through training. The researchers suggest that differences in the handedness of soccer players need to be further investigated and we recommend that effects of handedness differences must be taken into account when designing experiments into human cognition and soccer training.

\section{Conclusion}

Left-handedness was found to have a higher frequency in soccer players when compared with the general population. According to the hand preference, the proportion of those who use two feet equally increased. Reaction times and force's squat of the dominant hand and feet were better. When the groups were evaluated according to hand preferences, no significant difference was found between right-handed and left-handed players. Left footed players had more symmetrical leg strength than right footed counterparts. Training programs planned by taking into consideration soccer players' individual characteristics including footedness may increase performance and decrease injuries by lowering strength and reaction time asymmetry between legs and arms. While developing behaviors specific for soccer players, not only the genes but also the environmental factors, training, and experiences are determinative. Controlled studies should be conducted to achieve much clear results in the assessment of findings.

\section{References}

Akça, F., Çekin, R., \& Ziyagil, M. A. (2015). Influence of Hand Dominance on Targeted High Shot Performance in Young Men. Journal of Physical Education and Sports Science CBU, 10, 1-8.

Akpınar, S., \& Bicer, B. (2014). Why Left-handers/footers are overrepresented in some sports?, Monten. J. Sports Sci. Med, 3(2), 33-38.

Al Awamleh, A. A., Mansi, T., \& Alkhaldi, H. (2013). Handedness differences in eye-hand coordination and, Choices, simple reaction time of international handball players. Journal of Physical Education and Sport, 13(1), 78.

Beratis, I. N., Rabavilas, A. D., Kyprianou, M., Papadimitriou, G. N., \& Papageorgiou, C. (2013). Investigation of the link between higher order cognitive functions and handedness. J Clin Exp Neuropsychol, 35(4), 393-403. https://doi.org/10.1080/13803395.2013.778231

Brooks, R., Bussie re, L. F., Jennions, M. D., \& Hunt, J. (2004). Sinister strategies succeed at the cricket World Cup.Proceedings of the Royal Society of London B, 271, 64-66. https://doi.org/10.1098/rsbl.2003.0100

Cingoz, Y. E., Gürsoy, R., Ozan, M., Hazar, K., \& Dalli, M. (2018). Research on the Relation between Hand Preference and Success in Karate and Taekwondo Sports with Regards to Gender, Advances in Physical Education, 8, 308-320. 
https://doi.org/10.4236/ape.2018.83027

Coren, S. (1995). Differences in divergent thinking as a function of handedness and sex. Am J Psychol, 108(3), 311-325. https://doi.org/10.2307/1422892

Dane, S., \& Erzurumluoglu, A. (2003). Sex and handedness differences in eye-hand visual reaction times in handball players. International Journal of Neuroscience, 13(7), 923-929. https://doi.org/10.1080/00207450390220367

Erhan, S. E.,Gerek, Z., \& Bedir, D. (2018). The Role of Hand, Eye, and Ear Lateralization in the Sense of Rhythm of the Athletes, Journal of Education and Training Studies, 6(4a), 63-71. https://doi.org/10.11114/jets.v6i4a.3369

Fagan, F., Haugh, M., \& Cooper, H. (2017). The Advantage of Lefties in One-On-One Sports.

Fisekcioglu, I. B. (2011). Relations of Hand Preference, muscle power, lung function and reaction time in European right-handed Taekwondo players. World Applied Sciences Journal I, 12(8), 1288-1290.

Geschwind, N., \& Galaburda, A. (1987). Cerebral lateralization. Cambridge, MA: MIT Press.

Grace, T. G., Sweetser, E. R., \& Nelson, M. A. (1984) Isokinetic muscle imbalance and knee - joint injuries. Journal of Bone and Joint Surgery, 66, 734-739. https://doi.org/10.2106/00004623-198466050-00012

Grouios, G. (2004). Motoric dominance and sporting excellence: Training versus heredity. Perceptual and Motor Skills, 98, 53-66. https://doi.org/10.2466/pms.98.1.53-66

Gstöttner, M., Neher, A., Scholtz, A., Millonig, M., Lembetr, S., \& Raschner, C. (2009). Balance Ability and Muscle Response of the Preferred and non-preferred Leg in Soccer Players, Motor Control, 13, 218-231. https,//doi.org/10.1123/mcj.13.2.218

Gürsoy, R., Ziyagil, M. A., Şahin, M., \& Dane, Ş. (2009). Handedness, Achievement in Sport and Boxing Goldstein, S. R., \& Young, C. A. (1996). "Evolutionary" stable strategy of handedness in major league baseball. Journal of Comparative Psychology, 110, 164-169. https://doi.org/10.1037//0735-7036.110.2.164

Halpern, D., \& Coren, S. (1993). Left-Handedness and Life Span, A Reply to Harris. Psychological Bulletin, 114(2), 235-241. https,//doi.org/10.1037//0033-2909.114.2.235

Harris, L. J. (2007). In fencing, what gives left-handers the edge? Views from the present and the distant past. Laterality, Asymmetries of Body, Brain and Cognition.

Holtzen, D. W. (2000). Handedness and professional tennis. International Journal of Neuroscience, 105, 101-119. https,//doi.org/10.3109/00207450009003270

İmamoğlu, G. (2010). The Effect of Colors on Sportive Performance, Mustafa Kemal University Physical Education and Sports Science, 1(2), 40-52.

İmamoğlu, G., (2011). The Effect of Colors on Sportive Performance in Football, Ataturk University Physical Education and Sports Science, 7(2), 1-5.

İmamoğlu, O., \& Kılcıgil, E. (2007). Left-Handedness Issue at Reaction Time, Vital Capacity Values and Lateralization Distribution of Junior Football Players in Turkey, Spormetre Sciences, 5(3), 95-100

Leong, C. K. (1980). Laterality and Reading Proficiency in Children. Reading Research Quarterly, 15, 185-202. https,//doi.org/10.2307/747324

Loffing F, Sölter F, \& Hagemann N. (2014). Left Preference for Sport Tasks Does Not Necessarily Indicate Left-Handedness, Sport-Specific Lateral Preferences, Relationship with Handedness and Implications for Laterality Research in Behavioral Sciences. PLoS ONE, 9(8), 1-8. https,//doi.org/10.1371/journal.pone.0105800

Loffing, F., Schorer, J., Hagemann, N., \& Baker, J. (2012). On the advantage of being left-handed in volleyball, further evidence of the specificity of skilled visual perception. Atten Percept Psychophys, 74(2), 446-453. https,//doi.org/10.3758/s13414-011-0252-1

Nass, R. D., \& Gazzaniga, M. S. (1987). Cerebral lateralization and specialization in the human central nervous system. In, Plum, F. (Ed.), Handbook of Physiology, The Nervous System V. New York, Oxford University Press.

Onion, A. (2005). The Left-Handed Advantage, They May Have Higher Health Risks, But Lefties Enjoy Element of Surprise, Retrieved. July 3.

Peters, M., \& Durding, B. (1979). Left-handers and right-handers compared on a motor task. Journal of Motor Behavior, 11, 103-111. https,//doi.org/10.1080/00222895.1979.10735178

Porac, C., \& Coren, S. (1981). Lateral preference and human behavior. New York Springer Verlag. https,//doi.org/10.1007/978-1-4613-8139-6 
Raymond, M., Pontier, D., Dufour, A., \& Moller, A. (1996). Frequency-Dependent Maintenance of Left Handedness in Humans. Biological Sciences, 263(1377), 1627-1633. https,//doi.org/10.1098/rspb.1996.0238

Selçuk, M., Ziyagil, M. A., \& Şener, O. (2019). The Effect of Unilateral and Bilateral Foot Dominance on Sprinting Speed of Young Athletes, Journal of Education and Training Studies, 7(4), 187-192. https,//doi.org/10.11114/jets.v7i4.4150

Singh, I. (1970). Functional asymmetry in the lower limbs. Acta Anatomica, 77, 131-138. https,//doi.org/10.1159/000143535

Tan, Ü. (1988). The Distribution of Hand Preference in Normal Men and Women, İntern. J. Neuroscience, 41, 35-55. https,//doi.org/10.3109/00207458808985740

Trotter, R. (1974). Sinister Psychology, Tests and studies indicate that left-handedness need not and should not be considered an undesirable trait. Science News, 106(14), 220-222. https,//doi.org/10.2307/3959230

Turan, Z. (2010). Body Building from A to Z. I Write Publications (1st ed.). İstanbul.

Yamaner, F., \& İmamoğlu, G. (2018). Sport Performance Colors Power and Effect, Turkish Studies, 13(15), 515-520. https,//doi.org/10.7827/TurkishStudies.13602

Ziyagil, M. A., Gürsoy, R., Dane, S., \& Yüksel, R. (2010). Left hand wrestlers are more successful, Perceptual \& Motor Skills, 111(1), 65-70. https,//doi.org/10.2466/04.05.19.25.PMS.111.4.65-70

Ziyagil, M. A., Gürsoy, R., Dane, Ş., Türkmen, M., \& Çebi, M. (2015). Effects of handedness on the hand grip strength asymmetry in Turkish athletes, Comprehensive Psychology, 4(20), 1-6. https,//doi.org/10.2466/25.CP.4.20

\section{Copyrights}

Copyright for this article is retained by the author(s), with first publication rights granted to the journal.

This is an open-access article distributed under the terms and conditions of the Creative Commons Attribution license which permits unrestricted use, distribution, and reproduction in any medium, provided the original work is properly cited. 